\title{
ANALYSIS OF IRON CONTENT IN FOOD SUPPLEMENTS IN RELATION TO THE SAFETY OF THEIR USE
}

\author{
JOANNA SUROWIECKA ${ }^{1 *}$, PAWEŁ OLCZYK ${ }^{2}$, DIANA IVANOVA ${ }^{3}$, \\ YOANA KISELOVA-KANEVA ${ }^{3}$ and KATARZYNA KOMOSINSKA-VASSEV ${ }^{1}$
}

\author{
'Department of Clinical Chemistry and Laboratory Diagnostics, \\ ${ }^{2}$ Department of Community Pharmacy \\ Medical University of Silesia, Faculty of Pharmaceutical Sciences in Sosnowiec, \\ 41-200 Sosnowiec, Poland \\ ${ }^{3}$ Department of Biochemistry, Molecular Medicine and Nutrigenomics, \\ Faculty of Pharmacy, Medical University of Varna, 9002 Varna, Bulgaria
}

\begin{abstract}
The objective of the study was to test dietary supplements available on the European market with regard to their iron content. Twenty-nine vitamin and mineral supplements were investigated, with additional assessment of their mass homogeneity. Iron was determined by means of the $\mathrm{AAS}^{1}$ method following microwave mineralization of particular samples. Findings were compared to iron contents declared by producers. Tested supplements were analyzed with regard to the ratio between the amount of iron supplied to the body and the RDA ${ }^{2}$ for adults and pregnant women, as well as in view of the number of preparation pieces required to be taken in order to ensure the RDA in the groups included in the research. All preparations were characterised by high mass homogeneity. The iron content determined in the supplements was different from the values indicated by the producers on the packages. Four supplements did not meet the European requirements concerning acceptable limits of nutrient tolerance stated on the labels. Tolerance for iron value in food supplements indicated by producers on packages varied from RDAs for the studied groups. The dosage recommended by the producer was mostly different from the dosage necessary to meet the requirements for iron RDA in the studied groups.
\end{abstract}

Keywords: dietary supplements, food safety, iron, iron deficiency, pregnant women, microwave mineralization

Abbreviation: ${ }^{1} \mathrm{AAS}$ - Atomic Absorption Spectrometry, ${ }^{2} \mathrm{RDA}$ - recommended dietary allowance

The fast technological development it is currently observed in the world has resulted in changes in the food industry, which involve people more and more frequently reaching for concentrated sources of nutrients such as dietary supplements. Chemical composition and chemical processes that dietary supplement ingredients undergo create a significant new area of chemical food analyses, which is now developing dynamically. When analyzing the dietary supplement market, multivitamin and mineral preparations account for significant market value $(1,2)$.

In the United States, the safety and distribution of dietary supplements are controlled by the FDA (Food and Drug Administration), whose equivalent in EFSA (Europe is the European Food Safety Authority) (3). The act that directly regulates the implementation of dietary supplements in the USA is DSHEA (Dietary Supplement Health and Education Act) of 1994, whereas in Europe Directive 2002/46/EC, which unequivocally differentiates between food supplements and medicinal products (4-6).

From the point of view of a producer, the cost of placing DS (dietary supplements) on the market is significantly lower than that of registering a medicinal product. This causes that the quality of preparations is not confirmed by any investigations, which poses a risk of lawlessly counterfeiting the information on packages. Moreover, a lack of information on possible adverse reactions or interactions may mislead a consumer, suggesting that using the supplement brings only health benefits (7).

\footnotetext{
* Corresponding author: e-mail: surowiecka.joanna@gmail.com
} 
Based on the definition classifying dietary supplements as foodstuffs, they constitute a group of specific products present in the forms that enable patients to administer them on their own designed to complement dietary deficiencies. In view of large similarities, especially in the forms of administration, a lot of consumers do not notice the difference between dietary supplements and OTC (over-thecounter) drugs $(6,8)$.

Food supplements most commonly chosen worldwide include complex vitamin and mineral preparations (1). A popular element being a part of their composition is iron, which takes part in many vital biological processes, including oxygen transport and DNA and ATP synthesis as a cofactor of numerous enzymes $(9,10)$. Although iron metabolism is very economical, and the deposits necessary for normal courses of erythropoiesis and hemoglobin synthesis may even suffice for several years, factors such as bleeding or menstruation lead to irreversible iron loss, hence its demand in certain groups is higher (11).

Iron deficiency anemia (IDA) is one of the most commonly observed microelement deficiencies in the world (10). The groups characterized by the greatest need for iron include children, patients with malnutrition and pregnant women (12-14). Anemia is a body condition characterized by decreased blood hemoglobin levels compared to normal limits for a particular age and gender (15). Anemia impairs the delivery of oxygen to tissues, necessitating compensatory increased cardiac output. Anemia can manifest clinically as fatigue or lethargy, depression, and impaired cognitive function. However, mild cases of anemia may be asymptomatic, detectable only with laboratory testing. A physiological condition in which iron deficiency anemia poses a serious problem is pregnancy (16). This type of anaemia may entail severe health disturbances such as an increased risk of miscarriage and low birth weight. In pregnancy, iron deficiency anemia may reduce neonatal iron stores. Chronic anemia can also cause fetal neurological disorders because iron is involved in a course of neurogenesis and myelination $(11,17)$. Since anemia during pregnancy is a particularly dangerous phenomenon, controlling the iron level is crucial in this condition $(18,19)$.

According to literature up to $86 \%$ of women choose to take complex vitamin and mineral preparations, often in compliance with the doctors' recommendations, in order to take good care of their health and pregnancy. However, DS that producers recommend for pregnant women does not have to meet any special legal requirements of the amount of iron or acceptable contamination levels. As a result lack of choice between a tremendous amount of DSs compared to a small choice of OTC drugs as well as advertising campaigns, pregnant women much more frequently choose dietary supplements (20).

The main source of iron should be a balanced diet (21). In the case of an increased risk of IDA during pregnancy, suggested prophylaxis is 60 to 100 $\mathrm{mg}$ of elemental iron daily. For pregnant women with clinical symptoms of IDA including fatigue, weakness, persistent nausea or gastrointestinal problems, tachycardia, and shortness of breath, the average iron requirement is $1000 \mathrm{mg} / \mathrm{d}$ (22). Before starting the iron supplementation many factors influencing iron status should be taken into account in order to avoid iron overload with particular attention focused on dietary factors. Moreover, in order to detect clinically significant states related to iron deficiency, biochemical laboratory measurements including multiple estimation of iron blood level, serum ferritin (as an indicator of iron stores) and serum soluble transferrin (to evaluate functional iron deficit), should be applied (23).

The objective of the study was to analyze the chemical quality of vitamin and mineral dietary supplements available in the European market with regard to their iron content and, additionally, to assess their mass homogeneity, a parameter determining, for instance, the quality and standards of the manufacturing process. The findings were then compared with the information presented on the packages, regarding the declared iron content, and its ratio to the RDA for adults and pregnant women.

\section{EXPERIMENTAL}

The material subject to the study included 29 vitamin and mineral dietary supplements purchased on the European market, in pharmacies. Samples of dietary supplements came from Poland and were collected from April to June 2016. One component of the preparations was iron in the amount of 1 up to $60 \mathrm{mg}$ per piece. The supplements came in form of tablets, coated tablets, capsules, granules, and dragees. Tablets and coated tablets accounted for $69 \%$ of the material (20 preparations), capsules - for $17 \%$ (5 preparations), and dragees and granules - for the remaining $14 \%$ (4 preparations). The preparations varied in terms of their pharmaceutic form. The data concerning the analyzed preparations are presented in Table 1.

Until the samples were analyzed, they had been stored in a dry place, in room temperature. Three 


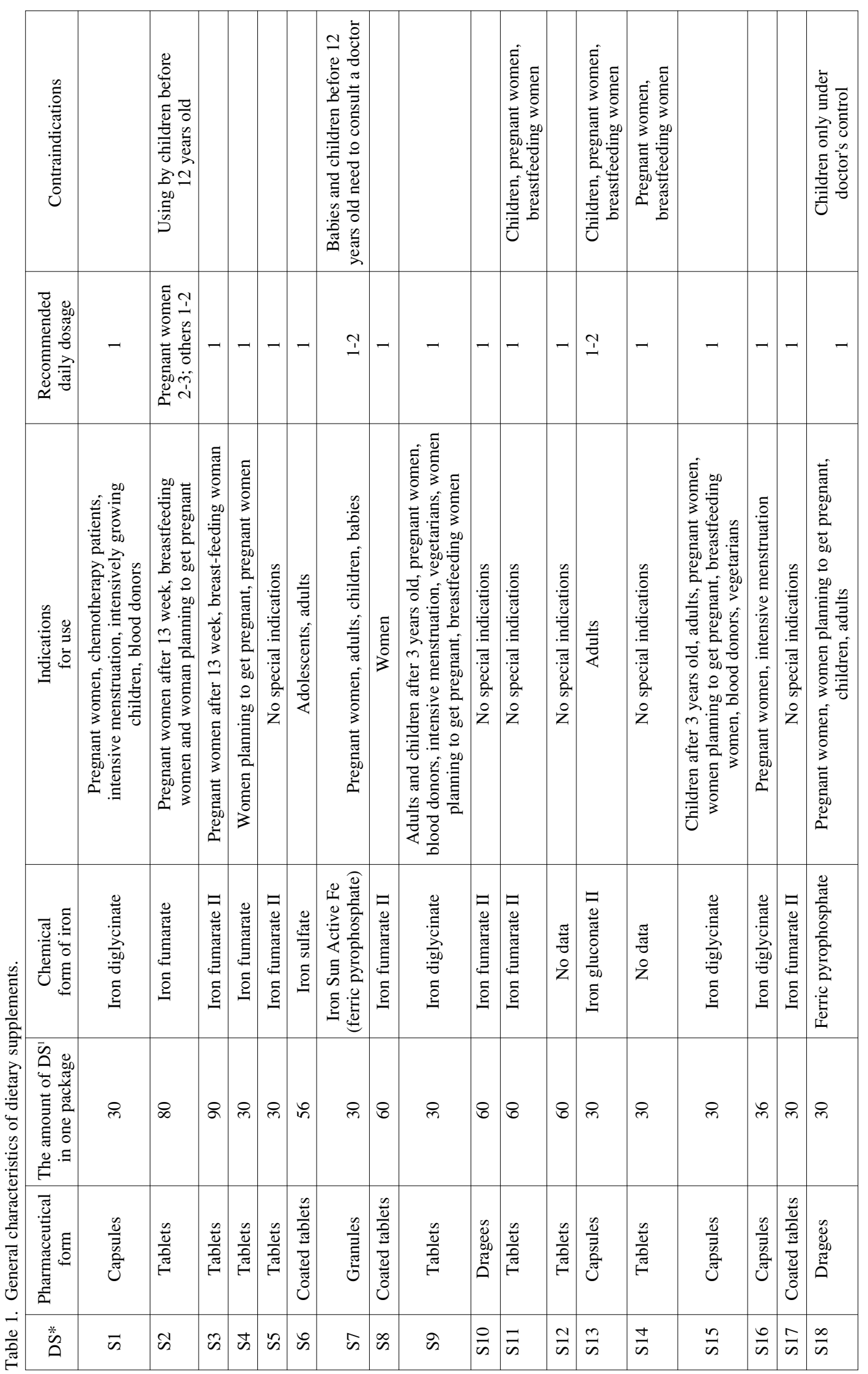




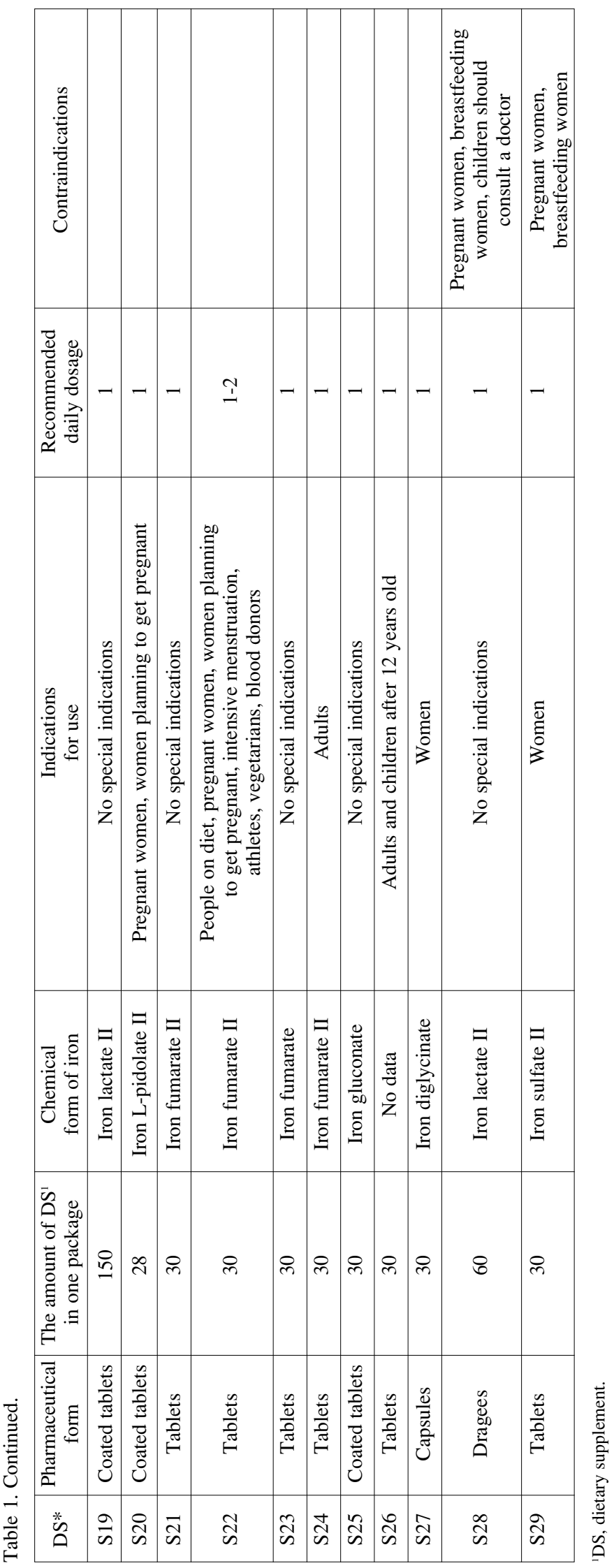


pieces of preparation were randomly selected out of each package and were next weighed to the nearest of $0.0001 \mathrm{~g}$ and smashed into homogenous mass in a porcelain mortar. In the case of capsules, the content was poured out, weighed to the nearest of $0.0001 \mathrm{~g}$, transferred to a porcelain mortar, and finally smashed into homogenous mass. As for coated tablets, the preparations were weighed to the nearest of $0.0001 \mathrm{~g}$, smashed in a porcelain mortar, and then passed through a sieve in order to remove the coating so that it did not interfere with the measurement. Test portions of $0.3 \mathrm{~g} \pm 0.01 \mathrm{~g}$ were obtained from the homogenate, which was followed by their dissolution in $5 \mathrm{~cm}^{3}$ of concentrated nitric acid and microwave mineralization in the Magnum II reactor by ERTEC (Wrocław, Poland). At all times the same parameters of dietary supplement mineralization were employed by experiment. Having completed the process, the samples were quantitatively transferred to $25 \mathrm{~cm}^{3}$ conical flasks and made up to the mark with deionized water. Cloudy solutions were filtered to ensure the exact measurement. In thus prepared samples the iron content was determined by the method of Flame Atomic Absorption Spectrometry (FAAS), with the use of the Varian SpectraAA 880 spectrometer. We used the FAAS method with the acetylene-air - oxidizing flame type with the application of the wavelength $248.3 \mathrm{~nm}$.

The mineralizer was operated by the Magnum V2-COM4 computer program. The process of mineralization was carried out in two subsequent cycles. In cycle I, the heating time was 2 minutes, and the microwave power $-360 \mathrm{~W}$, which amounted to $60 \%$ of the maximum mineralization power. The minimum and maximum temperatures in cycle I were $280^{\circ} \mathrm{C}$ and $285^{\circ} \mathrm{C}$, respectively, whereas the minimum and maximum pressure of the process equaled 17 and 20 bars. In cycle II, in turn, the heating time was 3 minutes at the mineralization power of $600 \mathrm{~W}$, which constituted $100 \%$ of the power. The minimum and maximum temperatures were $290^{\circ} \mathrm{C}$ and $295^{\circ} \mathrm{C}$, and the minimum and maximum pressure assumed the values of 42 and 45 bars, respectively. The determination of iron content in the food supplements by FAAS method was performed in the Institute of Water and Sewage Engineering of the Silesian University of Technology in Gliwice, Poland. The reliability of the applied determining method was verified using the NIST-SRM 1486 reference material. The iron content was determined in 6 mineralized samples of the reference material, and the following results were obtained: $\mathrm{Fe} 94.9 \pm 0.8$ $\mathrm{mg} / \mathrm{kg}$ (certified value of $99 \mathrm{mg} / \mathrm{kg}$ ), $\mathrm{RSD} \%=0.8 \%$, recovery of $95.9 \%$.
Based on the findings, a statistical analysis was conducted with the use of the Microsoft Office Excel 2007 spreadsheet and Statistica 13 program. The results were processed in the following stages:

1. Calculating the average mass of each of the tested supplements on the basis of the arithmetic mean of 10 randomly selected and weighed pieces of the supplement.

2. Calculating the standard deviation from the average mass of the tested supplements.

3. Converting the determined content of iron in one sample into the iron content in one piece of the tested preparation:

$$
\mathrm{C}_{\mathrm{Fe}}=\frac{\mathrm{C}_{1}}{\mathrm{~m}} \times 1000[\mathrm{mg}]
$$

$\mathrm{C}_{\mathrm{Fe}}$ - iron content in one piece of a dietary supplement [mg],

$\mathrm{C}_{1}$ - iron content in a sample determined by the Atomic Absorption Spectrometry method $[\mu \mathrm{g} / \mathrm{g}]$,

$\mathrm{m}-$ mass of one piece of a food supplement $[\mathrm{g}]$.

4. Calculating the percentage difference between the declared and determined values in a preparation:

$$
\Delta_{\mathrm{Fe}}=\frac{\mathrm{d}-\mathrm{o}}{\mathrm{o}} 100[\%]
$$

$\Delta_{\mathrm{Fe}}-$ percentage difference between the declared and determined contents [\%],

$\mathrm{d}$ - declared content [mg],

$\mathrm{o}$-determined content [mg].

5. Calculating the iron content determined in one piece of a dietary supplement with regard to the recommended dietary allowance (RDA [\%]) according to the European standards for adults and pregnant women.

6. Calculating the hypothetical proper dosage of the tested supplements aimed at observing the recommendations of daily intake by the target groups: adults and pregnant women, in view of the determined iron contents.

\section{RESULTS}

The investigated dietary supplements were compared in view of the ratio between the iron content determined and that declared on the package by the producer. The determined iron contents proved both lower and higher than those declared by the producers. For $52 \%$ of the preparations the determined iron content was higher than the declared content, and for $48 \%$ of the supplements - it was lower. Relative differences between the determined and declared values $\left(\Delta_{\mathrm{Fe}}\right.$ ) ranged from $+56 \%$ to $83 \%$. In the case of $69 \%$ of preparations the calculated value amounted to $+/-9 \%$. The issue of the dis- 
crepancy between the composition as declared by the producer on a package and the actual contents of a dietary supplement was also shown in the work by Szterk et al., 2018 (7), where attention was drawn to a very significant role of contamination content, which does not have to be declared by producers in any food supplements, including those dedicated for example to pregnant women and infants. Likewise, in a study by Krawczyk, 2014 (24), dietary supplements were tested for the presence of heavy metals displaying high toxicity for the body. Toxicity control is one of the methods of qualitative control of medicinal products applied in clinical research that food supplements are not subject to.

At the next stage, the findings regarding determined iron contents were compared with the acceptable deviation from the values declared on the labels for vitamins and minerals in food supplements in accordance with the guidelines from the European Commission, 2012 (25). According to the guidelines the acceptable tolerance limits are $+45 \%$ and $-20 \%$ in relation to the value indicated on a foodstuff label. $14 \%$ of the studied supplements (4 preparations) did not meet the standards. One preparation exceeded the upper limit, and the other three did not reach the minimal value. The remaining supplements were within the normal limits dictated by the European standards.

The following step involved comparing the tolerance for iron value in food supplements for iron indicated on the food supplement packaging to the daily intake recommended to two target groups: adults and pregnant women. According to the European guidelines, the recommended daily allowance for iron is accepted at the level of $18 \mathrm{mg}$ for adults and $27 \mathrm{mg}$ for pregnant women $(7,26)$. For the group of adults, in the case of $97 \%$ (28 preparations), the value of recommended dietary allowance proved to be lower than the tolerance for iron value in food supplements provided on the packaging. As for the daily intake recommended for pregnant women, this was true about $100 \%$ of the preparations. The difference between the tolerance for iron value in food supplements indicated on the package and the RDA calculated on the basis of the determined iron contents ranged from 1.58 to 98.67 for adults and from 3.44 to 209.78 for pregnant women. For $55 \%$ (16 preparations) the difference value was higher than 20 in the group of adults and did not exceed the value of 100 for any of the preparations. In the group of pregnant women, in turn, it was higher than 20 for $83 \%$ (24 preparations) and exceeded the value of 100 for $10 \%$ (3 preparations). Then the tested supplements were analyzed in rela- tion to their use in both target groups, namely adults and pregnant women. Based on the European normal limits of the daily intake recommended for women, it was calculated how many supplement pieces should be administered to complement the daily demand and to meet the normal limit, taking into account the iron content determined in a preparation $(7,26)$. The findings were juxtaposed to the minimal recommended daily intake of the preparation as indicated by the producer on the packaging. In the analysis of the group of adults, it was in 3\% (1 preparation) that the calculated dosage overlapped with the lowest recommended dosage indicated by the producer on the package. In the case of $76 \%$ of supplements (22 preparations) the calculated dosage was higher, including 34\% (10 preparations) where the calculated dosage was more than twice as high as that given on the package. For $21 \%$ (6 preparations), however, it was lower. In the analysis of the group of pregnant women, it was in $12 \%$ (3 preparations) that the dosage overlapped with the minimum recommended dosage indicated by the producer, and for $3 \%$ ( 1 preparation) the calculated dosage coincided with the additional dosage recommended for pregnant women as indicated by the producer. For $83 \%$ ( 24 preparations) the dosage given by the producer was lower than that calculated in the study, including 34\% (10 preparations) where the dosage recommended by the producer was at least 3 times as low. For 3\% (1 preparation) the calculated dosage was lower than that recommended by the producer.

In the case of two supplements, S27 and S13, the calculated dosage was manifold that indicated by the producer on the package. In order to satisfy the recommended daily iron allowance, an adult would need to take in 18 pieces of supplement S27 and 21 pieces of supplement S13, while a pregnant woman would need 27 and 32 pieces, respectively. As for the remaining preparations, a descriptive statistical analysis for the normal skew distribution was carried out.

As for the remaining 27 food supplements, in the case of dosage recommended to adults, the average number of preparation pieces that should be administered and the median were 1.91 and 1.38 pieces of preparation, respectively. The dosage ranged from 0.29 to 5.84 pieces daily. For $25 \%$ of the supplements, the proper dosage was lower than or equal to 1.03 pieces per day and higher than or equal to 2.72 pieces, with a standard deviation of 1.43 .

In the case of pregnant women, the average number of capsules to be taken in order to satisfy the recommended daily allowance was 2.87 , whereas 
the median amounted to 2.07. The dosage ranged from 0.43 to 8.77 pieces. For $25 \%$ of the preparations, the dosage was lower than or equal to 1.55 and higher than or equal to 4.08 , with a standard deviation of 2.15 .

All the above-mentioned findings are presented in Table 2.

The investigated preparations were also checked with regard to their mass homogeneity. This was achieved by weighing 10 randomly chosen pieces taken out of every package of the preparations subject to study. The standard deviation for all the tested supplements was lower than 0.03. The standard deviation values are collected in Table 3.

\section{DISCUSSION AND CONCLUSION}

In view of growing popularity of dietary supplements in all age groups all over the world, a fact reflected in numerous publications, such as Qato et al., 2016 (27) and Bishnoi and Yadav, 2017 (29), there is research carried out in order to test their quality $(1,2)$. Since supplements are classified as foodstuffs, they do not need to meet the legal requirements established for medications, and, unlike medicinal products, they are not registered. In consequence, there are no strict qualitative or quantitative standards these products have to meet before they are placed on the market, and the only regulations they are subject to are those concerning food products. In the present study, 29 dietary supplements were tested, and the iron content declared by the producer on the packaging was compared to the content determined in the preparations by means of the FAAS method. The findings differed from the values indicated on the packaging. Although there exist standards concerning deviations from the amounts of foodstuff components by the European Commission Directorate-General for Health and Consumers $(21,25,29)$, before registering a dietary supplement the producer is not obliged to present the documents confirming that the product meets the standards. Four of the tested preparations did not comply with those regulations, even though they are not restrictive at all, especially compared to the qualitative and quantitative control for medicinal products, which takes place both before and after product registration. Moreover, comparing the dietary reference values indicated by the producer to the actual daily intake based on the determined values revealed that both for adults and pregnant women the values were considerably different. For both groups, in nearly $100 \%$ of the preparations, the actual amount needed to satisfy the daily requirement was significantly lower than that stated by the producer. The fact that on the market there many dietary supplements not meeting the standards in force clearly shows that these preparations are not at all controlled with regard to the amounts of their particular ingredients; also, the information provided on the package by the producers is not verified.

As the quality of dietary supplements is controversial, it is doubtful whether their application is safe. Adverse effects of both iron deficiency and excess may be most dangerous in such groups as children and pregnant women. In pregnant women, however, requirements for vitamins and minerals are large, and additional supplementation decreases the risk of anemia, and thus of serious consequences for the health of the fetus. Screening examinations of pregnant women performed in Europe have shown that cases of iron deficiency anemia occurred more frequently in pregnant women who did not apply iron supplementation. This was especially notable in the third trimester of pregnancy, where iron deficiency may result in premature labor. Those women, in turn, who regularly supplemented iron during pregnancy were at a significantly lower risk of this element deficiency (30). No matter how important the correct iron level is during pregnancy, our study has shown that dietary supplements recommended for pregnant women are not adjusted to the standards regarding the right amounts of iron that should be supplied. In the case of $86 \%$ (25 preparations) the dosage recommended by the producer was one piece of the preparation. For 3\% (1 preparation S2) the producer specified the daily dosage for a pregnant woman as $2-3$ pieces. For $10 \%$ ( 3 preparations) the producer indicated the dosage as 1-2 pieces a day, without determining the target group for the minimum and maximum recommended dosage. $38 \%$ of the tested supplements (11 preparations) were alleged by the producer as preparations recommended for pregnant and breastfeeding women, who, according to the European standards concerning recommended daily allowance, present significantly higher iron requirements than for example males, which poses the risk of overdosing the preparation, should the iron content in one piece of the preparation be adjusted to the needs of pregnant women. Nevertheless, it was only in one preparation that the producer separately indicated the dosage for pregnant women. Failure to adjust the tested supplements to the needs of particular groups of recipients is also reflected in the findings of this research, where the right dosage of the preparations calculated with regard to the recommended daily 


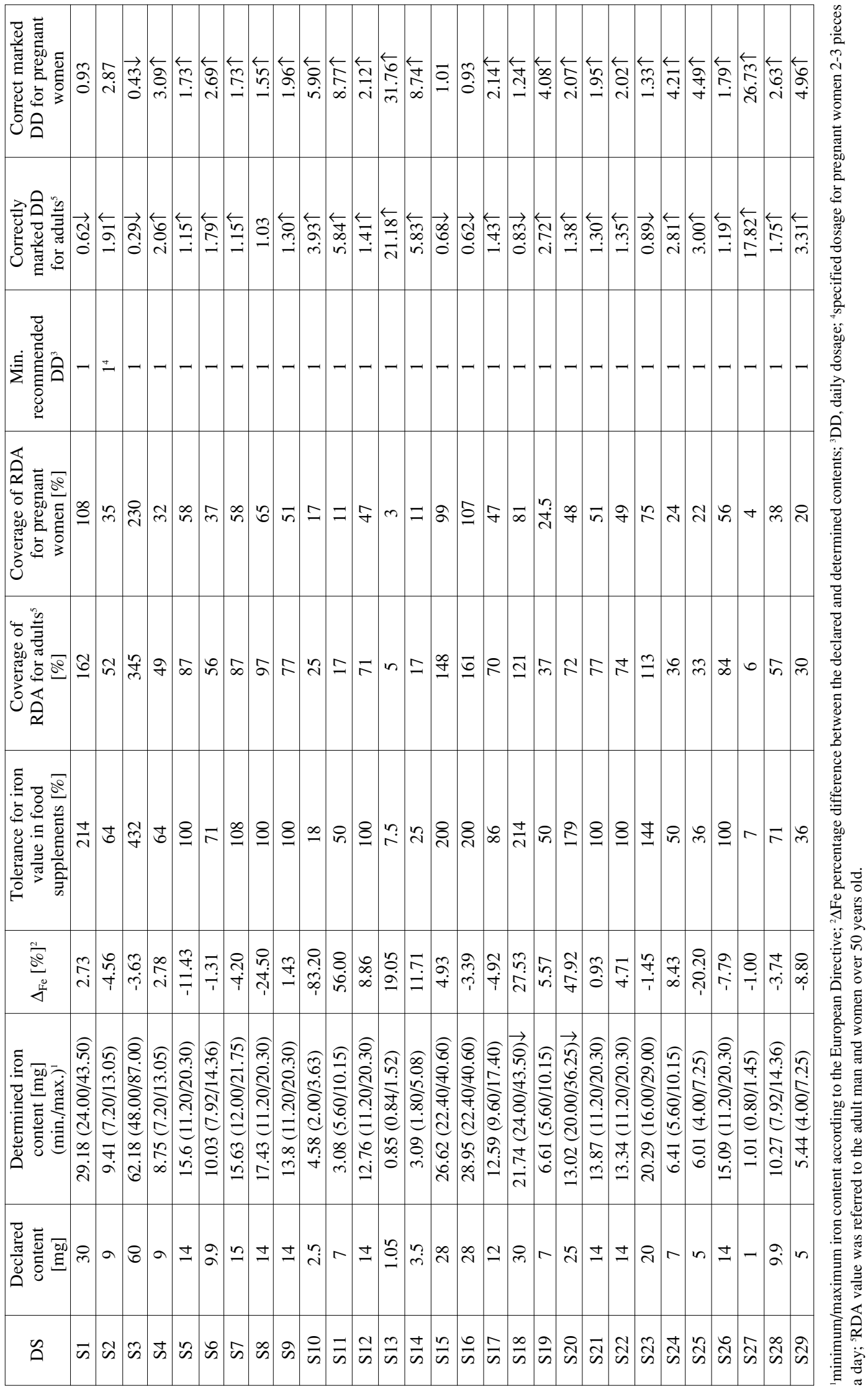


allowance for adults and pregnant women was in most cases several times higher than that indicated by the producer. In the case of two preparations, S13 and S27, the calculated dosage was significantly different from that given on the packaging. Bearing in mind that one package contains 30 pieces, to satisfy the daily demand for iron, an adult would need to take in more than half the package of supplement S27 and 2/3 of the package of supplement S13. To satisfy her RDA, a pregnant woman would have to ingest almost the whole package of supplement S27 and more than one package of supplement S13.

For $38 \%$ of the preparations included in the study $(\mathrm{n}=11)$, the producer did not specify the target group that should apply a given preparation, which may mislead a consumer, giving the impression that the supplement may be taken by both an adult and a child, irrespective of the age, gender and physiological status. Only $28 \%$ (8 preparation) possessed contraindications for their use indicated by the producer,

Table 3. Mass homogeneity of dietary supplements.

\begin{tabular}{|c|c|c|}
\hline Dietary supplements & $\begin{array}{l}\text { Average weight of the } \\
\text { pharmaceutical form of the } \\
\text { dietary supplements [g] }\end{array}$ & $\mathrm{SD}^{*}$ \\
\hline S1 & 0.31 & 0.01 \\
\hline S2 & 0.52 & 0.01 \\
\hline S3 & 1.33 & 0.01 \\
\hline S4 & 1.16 & 0.00 \\
\hline S5 & 1.19 & 0.00 \\
\hline S6 & 0.49 & 0.01 \\
\hline S7 & 1.03 & 0.02 \\
\hline S8 & 1.35 & 0.03 \\
\hline S9 & 0.30 & 0.01 \\
\hline $\mathrm{S} 10$ & 0.68 & 0.01 \\
\hline S11 & 0.66 & 0.01 \\
\hline $\mathrm{S} 12$ & 0.66 & 0.00 \\
\hline S13 & 0.40 & 0.00 \\
\hline S14 & 0.63 & 0.00 \\
\hline S15 & 0.32 & 0.01 \\
\hline S16 & 0.42 & 0.02 \\
\hline S17 & 0.94 & 0.01 \\
\hline S18 & 0.96 & 0.03 \\
\hline S19 & 0.93 & 0.00 \\
\hline S20 & 0.81 & 0.01 \\
\hline S21 & 0.14 & 0.00 \\
\hline S22 & 0.36 & 0.01 \\
\hline S23 & 0.52 & 0.00 \\
\hline S24 & 0.37 & 0.00 \\
\hline S25 & 0.27 & 0.02 \\
\hline S26 & 1.44 & 0.01 \\
\hline S27 & 1.07 & 0.01 \\
\hline S28 & 0.54 & 0.01 \\
\hline S29 & 1.37 & 0.01 \\
\hline
\end{tabular}

The samples number of 0.00 SD value: 9 ; The samples number of $0.01 \mathrm{SD}$ value: 15 ; The samples number of 0.02 SD value: 3 ; The samples number of $0.03 \mathrm{SD}$ value: $2 ; * \mathrm{SD}$, standard deviation. 
which also gives the wrong impression of the lack of side effects of the applied supplement. This may even lead to a consumer resigning from applying registered preparations and choosing seemingly safer and more universal dietary supplements. This legal loophole is increasingly taken advantage of by the producers in view of significantly lower costs of placing products on the market, as they are not obliged to include package leaflets or to inform patients about possible side effects without any legal consequences $(7,26)$. In the case of medicinal products, the target group of recipients of a product needs to be strictly determined, and the exact dosage specified, often expressed in terms of the amount per kilogram of body weight, and every new indication has to be confirmed by clinical research and documented, according to the requirements of the European Medicines Agency or equivalents of this body in the United (31).

In the present study, sample homogeneity was also tested for the 29 preparations, which had the dominating form of tablets and coated tablets $(69 \%$ of the preparations). Based on the calculated standard deviation a high level of mass homogeneity in the tested preparations was found. The standard deviation for all the studied supplements was below 0.03. Similar conclusions were drawn in the study by Pawlak et al., 2016 (30), in which 20 vitamin and mineral preparations containing iron were tested. The fact of obtaining high mass homogeneity of the tested preparations is not coupled with confirmation of the supplement quality by the study, as dietary supplements are not under pharmacopeia control. All these observations point to the necessity of implementing more restrictive provisions regulating the registration of dietary supplements, as well as regular qualitative and quantitative control over the correctness of the composition indicated by the producer in relation to the actual contents. This will increase the safety of food supplements.

The investigated preparations were characterized by high mass homogeneity. The findings concerning the ratio between the determined and declared iron contents differed depending on a kind of supplement. Four supplements did not meet the European requirements concerning acceptable limits of content deviations from the values indicated on a package. For nearly all tested supplements the dosage indicated by the producer did not refer to the dosage calculated on the basis of the recommended dietary allowance for two target groups, namely adults and pregnant women. Thus, we conclude that the use of dietary supplements could be taken into consideration only in the case of - biochemically/ diagnostically proved - trace elements deficiencies.

\section{Acknowledgments}

We thank the Institute of Water and Sewage Engineering of the Silesian University of Technology in Gliwice, Poland for the determination of the iron content in the dietary supplements by the FAAS method.

This study was supported by the funding from the Medical University of Silesia (grant no. KNW$1-083 / \mathrm{N} / 9 / \mathrm{Z})$.

\section{Conflicts of interest}

The authors declare no conflict of interest.

\section{REFERENCES}

1. Andrews K.W., Roseland J.M, Gusev P.A., Palachuvattil J., Dang P.T., et al.: Am. J. Clin. Nutr. 105, 526 (2017).

2. Value of the dietary supplements market in Europe in 2015 and 2020, by country. Statista (2018).

3. Wierzejska R., Jarosz M., Siuba M., Rambuszek M.: Rocz. Panstw. Zakl. Hig. 65, 317 (2014) (in Polish).

4. Rocha T., Amaral J.S., Oliveira M.B.P.P.: CRFSFS 15, 43 (2016).

5. Directive 2002/46/EC of the European Parliament and of the Council of 10 June 2002 on the approximation of the laws of the Member States relating to food supplements (2002).

6. Sax J.K.: Am. J. Law Med. 41, 374 (2015).

7. Szterk A., Zmysłowski A., Bus K.: Food Chem. 243, 243 (2018).

8. Akabas S.R., Vannice G., Atwater J.B., Cooperman T., Cotter R., Thomas L.: J. Acad. Nutr. Diet. 116, 1370 (2016).

9. Gozzelino R., Arosio P.: Int. J. Mol. Sci. 17, 130 (2016).

10. Camaschella C.: N. Engl. J. Med. 372, 1832 (2015).

11. Pasricha S.R., Low M., Thompson J., Farrell A., De-Regil L-M.: J. Nutr. 144, 906 (2014).

12. Peyrin-Bisoulet L., Williet N., Cacoub P.: AJCN 102, 1585 (2015).

13. Santiago P.: Sci. World J. 2012, 846 (2012).

14. Guideline. Iron Supplementation in postpartum women. WHO, 2016.

15. Mahmoud H.H., Muddathir A.M., Osman S.E.M., Alkhawad M.A., Awadia K.: Sudan. J. Public Health 9, 33 (2014).

16. Abdalla S.E., Abdelgader E.A., Diab T.A., et al.: Merit Res. J. Microbiol. Biol. Sci. 1, 21 (2013). 
17. Radlowski E.C., Johnson R.W.: Front. Hum. Neurosci. 7, 1 (2013).

18. Augusta de Sá S., Willner E., Aguiar Duraes Pereira T., Rosse de Souza V., Teles Boaventura G., Blondet de Azeredo V.: Nutr. Hosp. 32, 2071 (2015)

19. Bah A., Wegmuller R., Cerami C., Kendall L., Pasricha S.R.: et al.: BMC Pregnancy Childbirth 16, 157 (2016).

20. Picciano M.F., McGuire M.K.: Am. J. Clin. Nutr. 89, 663 (2009).

21. Wong L., Smith S., Gilstrop M., Derman R., Auerbach S., et al.: Am. J. Hematol. 91, 590 (2016).

22. Cantor A.G., Bougatsos C., Dana T., Blazina I., McDonagh M.: Ann. Intern. Med. 162, 566 (2015).

23. Abbaspour N., Hurrell R., Kelishadi R.: J. Res. Med. Sci. 19, 164 (2014).

24. Krawczyk M.: J. Pharm. Biomed. Anal. 88, 377 (2014).

25. Guidance document for competent authorities for the control of compliance with EU legislation. European Commission (2012).
26. Panel on Micronutrients. Washington (DC): National Academies Press (US); Dietary Reference Intakes for Vitamin A, Vitamin K, Arsenic, Boron, Chromium, Copper, Iodine, Iron, Manganese, Molybdenum, Nickel, Silicon, Vanadium, and Zinc. Institute of Medicine (2001)

27. National Institutes of Health. Dietary Supplement Label Database. NIH (2018).

28. Qato D.M., Wilder J., Schumm L.P., Gillet V., Alexander G.C.: JAMA Intern. Med. 176, 473 (2016).

29. Bishnoi V.K., Yadav P.: IJARCSMS 5, 65 (2017).

30. Pawlak A., Rajczykowski K., Loska K., Ahnert B., Wiechuła D.: Bromat. Chem. Toxycol. 49, 23 (2016).

31. Milman N., Taylor C.L., Merkel J., Brannon P.M.: Am. J. Clin. Nutr. 106, 1655S (2017).

32. Committee for Medicinal Products for Human Use. Guideline on the chemistry of active substances. European Medicines Agency (2016).

(c) 2020 by Polish Pharmaceutical Society. This is an open-access article under the CC BY NC license (c) (1) (8) (http://creativecommons.org/licenses/by-nc/4.0/). 